$W \quad$ - volume of catalyst charged in a unit length of a packed bed reactor

$X=$ conversion of $A$ component

$=$ longitudinal length in a packed-bed reactor

$=$ defined in the reaction scheme (B)

$=$ volume ratio of catalytic aggregates to the total catalyst volume

$\tau \quad=\frac{W}{F} z$, contact time of a packed-bed reactor

$\eta \quad=\eta_{1} / \eta_{2}$

suffix 1 and 2 refer to the first and second step reaction, respectively

\section{Literature Cited}

1) АНДРИАНОВА, Т. И., О. М. ТОДЕС: Zh. Fiz. Khim. $30,522(1956)$
2) Carberry, J. J.: A. I. Ch. E. Journal, 12, 20 (1966)

3) Hirasa, K.: the doctoral thesis, Univ. of Tokyo, Japan (1966)

4) Kano, H., K. Kanazuka: Kogyo Kagaku Zashi, 61, 1157 (1958)

5) Komiyama, H., H. Inoue: J. Chem. Eng. Japan, 1, 142 (1968)

6) Orzechowski, A., K. E. MacCormack: Can. J. Chem., 32, 388 (1954)

7) Tabata, M., F. Yoshida, T. Kiryu: Kogyo Kagaku Zashi, 63, $268(1960)$

8) Thiele, E. W.: Ind. Eng. Chem., 31, 916 (1939)

9) Wan Shen-wu: Ind. Eng. Chem., 45, 234 (1953)

10) Weisz, P. B., E. W. Sweglar: J. Phys. Chem., 59, 823 (1955)

11) Wheeler, A. : Catalysis (Edited by Emmett P. H.), Vol. II, 105 (1955)

\title{
GASIFICATION OF POROUS CARBON BY CARBON DIOXIDE*
}

\author{
KUNIO YOSHIDA AND DAIZO KUNII \\ Deparment of Chemical Engineering, \\ University of Tokyo, Tokyo
}

\begin{abstract}
A method of analysis is presented for the reaction between a porous solid and a gas when the diffusion resistance is significant. The kinetic expression used is linear with respect to the concentration of reacting gas.

As a typical example, experiments of gasification of graphite sph:res with carbon dioxide were carried out and the results were compared with the proposed model, where the change of the porous structure due to the reaction is considered. The computed values agreed favorably with the experimental data for the early stage of the reaction.
\end{abstract}

\section{Introduction}

Since the pioneering investigation of Thiele ${ }^{11}$, a number of researchers have studied the transport phenomena in the reaction taking place heterogeneously on the surface of a solid. Little attention, however, has been paid to the studies on heterogeneous reaction ${ }^{1,3,4,5,8,10,14,15)}$ in which the solid itself is consumed, as in the combustion of coal.

The reaction kinetics in such a case have usually been analyzed by a well known model, the core model, in which reaction is assumed to take place on the geometric surface of the unreacted mass. In most instances, the solid phase has a large specific area because of the porous structure composed of fine particles. The reacting gas diffuses into the interior of the solid, where the major part of the reaction occurs, as described by Rossberg and Wicke ${ }^{10}$.

The gasification rate of carbon is relatively slow unless exposed to elevated temperatures. It must be considered that carbon dioxide penetrates into the porous carbon mass, causing the reaction within the mass and

* Received on April 11, 1968 on the surface.

In the present work, an attempt was made to provide a simple model to predict the rate of reaction between a porous graphite and carbon dioxide, $\mathrm{C}+\mathrm{CO}_{2} \rightarrow 2 \mathrm{CO}$, where the concentration gradient within the pore system was considered.

\section{Proposed Model}

Fig. 1 is proposed to represent this system. A sphere of porous graphite is considered to be an assemblage of rectangular volume elements, side lengths of $r d \varphi$ and $r \sin \varphi d \theta$, respectively with thickness of $d r$, and with each volume element containing a rectangular pore as indicated in the figure. It is assumed that the reaction takes place on the four side walls of each pore, excluding the two sides, which are entrance and exit of pore as shown with dashed lines in Fig. 1.

The derivation of the fundamental equations of material balance is subject to the following restrictions :

1. The reaction is first-order.

2. Temperature gradient within the solids is negligible, because the temperature difference between the surface and center is expected to be smaller than $7^{\circ} \mathrm{C}$ 
according to Prater's estimation'.

3. The change in moles due to the reaction is negligible in the range of low conversion under consideration. Thus, the effective diffusivity of gas is assumed to be expressed as $\varepsilon^{2} D^{12)}$.

The material balance for the volume element gives

$$
\begin{array}{r}
D \varepsilon^{2} \sin \varphi d \theta d \varphi\left\{r^{2} \frac{\partial^{2} C}{\partial r^{2}}+2 r \frac{\partial C}{\partial r}\right\} \\
-2 k C r\{\sin \varphi d \theta+\varepsilon d \varphi\}=0
\end{array}
$$

The volume change of the pore resulting from the reaction is

$$
\sin \varphi d \theta d \varphi \frac{\rho}{M} r \frac{\partial \varepsilon}{\partial t}=2 k C\{\sin \varphi d \theta+\varepsilon d \varphi\}
$$

Suppose that the length of each side of the volume element at the sphere is equal to $L$,

$$
R_{0} d \varphi=R_{0} \sin \varphi d \theta=L
$$

Eqs. (1) and (2) can be expressed in dimensionless forms,

$$
\begin{aligned}
& \frac{\partial^{2} \psi}{\partial \eta^{2}}+\frac{2}{\eta} \frac{\partial \psi}{\partial \eta}-2 \frac{1+\varepsilon}{\varepsilon^{2}} \alpha^{2} \frac{1}{\eta} \psi=0 \\
& \frac{\partial \varepsilon}{\partial \tau}=2 C_{b} \frac{M}{\rho} \alpha^{2}(1+\varepsilon) \frac{1}{\eta} \psi
\end{aligned}
$$

where

$$
\begin{aligned}
& \phi=\frac{C}{C_{b}}, \quad \eta=\frac{r}{R_{0}}, \quad \tau=\frac{D}{R_{0}{ }^{2}} t \\
& \text { and } \alpha=R_{0} \sqrt{\frac{k}{L D}}
\end{aligned}
$$

The boundary conditions

$$
\phi(\tau, 1)=1.0, \quad \phi(0,1)=1.0,\left.\quad \frac{\partial \psi}{\partial \eta}\right|_{\eta=0}=0
$$

The finite-difference forms of Eqs. (3) and (4) are ob. tained, respectively, as

where

$$
a_{n} \psi_{n+1}+b_{n} \phi_{n}+d_{n} \phi_{n-1}=0
$$

$$
\begin{aligned}
& a_{n}=\frac{1}{\Delta \eta^{2}}+\frac{1}{\eta_{n} \Delta \eta} \\
& b_{n}=-\left[\frac{2}{\Delta \eta^{2}}+2 \frac{1+\varepsilon_{n}}{\varepsilon_{n}{ }^{2}} \alpha^{2} \frac{1}{\eta_{n}}\right] \\
& d_{n}=\frac{1}{\Delta \eta^{2}}-\frac{1}{\eta_{n} \Delta \eta} \\
& \varepsilon_{n, \tau+\Delta \tau}=2 C_{b} \frac{M}{\rho} \alpha^{2}\left(1+\varepsilon_{n, \tau}\right) \frac{\phi_{n}}{\eta_{n}} \Delta \tau+\varepsilon_{n, \tau}
\end{aligned}
$$

Then Eq. (6) and two boundary conditions of Eq. (5) can be brought compactly to the matric equation.

$$
(A)(\phi)=(B)
$$

where

$$
(\phi)=\left[\begin{array}{c}
\phi_{1} \\
\phi_{2} \\
\vdots \\
\phi_{n}
\end{array}\right], \quad(B)=\left[\begin{array}{c}
-d_{1} \\
0 \\
\vdots \\
0
\end{array}\right]
$$

and

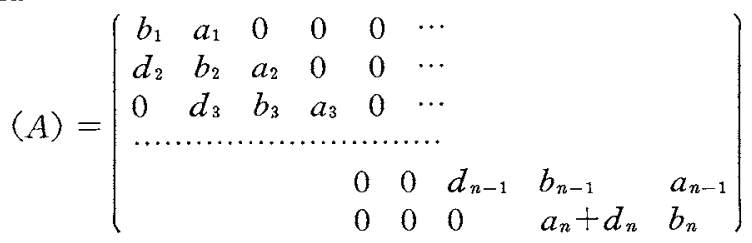

This can be numerically solved by means of a digital computer. When the value of $\varepsilon_{i}(0 \leqq i \leqq n)$ in Eq. (8) exceeds unity, then the value of $\phi_{i}$ is taken as unity.

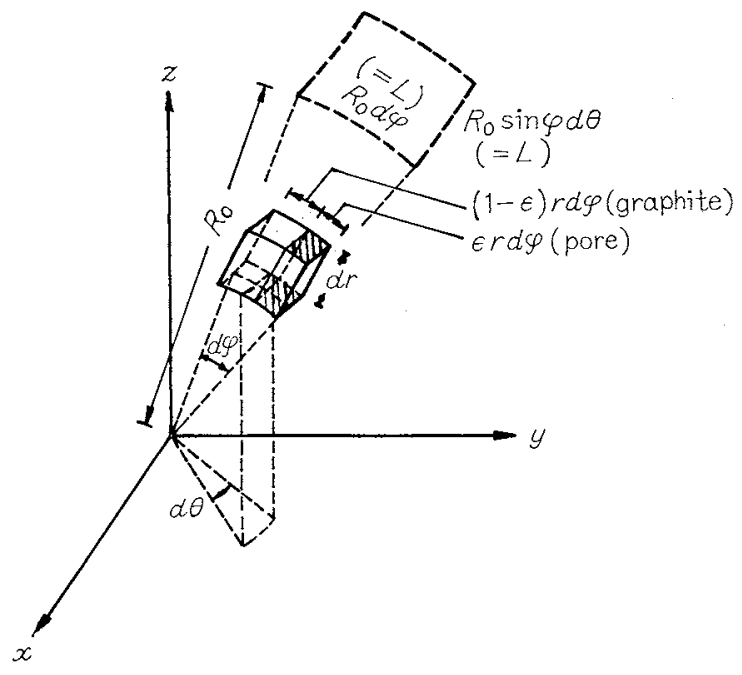

Fig. 1 Volume element of proposed model in spherical coordinates

This means that the solid is consumed to this position and the surface of the $i+1$ th element is exposed to fresh gas of concentration $C_{b}$.

The results of the computation made on OKITAC 5090 are shown in Fig. 2. It is seen from the figure that the concentration of gas in the solid increases progressively with the increase of pore size owing to the reaction, and this change depends on the Thiele module, $\alpha$.

The following values can then be calculated from the distributions of concentration and porosity in the solids. Overall porosity $\bar{\varepsilon}$ :

$$
\vec{\varepsilon}=\frac{4 \pi R^{3} \int_{0}^{\nu} \varepsilon(\eta) \eta^{2} d \eta}{4 / 3 \pi R^{3}}=3 \int_{0}^{\nu} \varepsilon(\eta) \eta^{2} d \eta
$$

Conversion $Y$ :

$$
Y=\frac{W_{0}-W}{W_{0}}=1-\frac{\nu^{3}}{0.71}\left[1-3 \int_{0}^{\nu} \varepsilon(\eta) \eta^{2} d \eta\right]
$$

Surface area of the volume element is

$$
2 r d r(\sin \varphi d \theta+\varepsilon d \varphi)=2 R L(1+\varepsilon) \eta d \eta
$$

Therefore overall surface area $S$ :

$$
S=\frac{4 \pi R^{2}}{L^{2}} \cdot 2 R L\left[\frac{1}{2}+\int_{0}^{R} \varepsilon(\eta) \eta d \eta\right]
$$

Initial reaction surface area $S_{0}$ for $\varepsilon_{0}=0.29$ :

$$
S_{0}=\frac{8 \pi R_{0}{ }^{3}}{L}\left[\frac{1}{2}+\frac{1}{2}(0.29)\right]=\frac{8 \pi R_{0}{ }^{3}}{L}(0.645)
$$

Surface area ratio $S / S_{0}$ :

$$
S / S_{0}=\nu^{3}\left[\frac{0.5+\int_{0}^{R} \varepsilon(\eta) \eta d \eta}{0.645}\right]
$$

Effectiveness factor $E_{f}$ :

$$
\begin{aligned}
E_{f} & =\frac{\left(2 R L \int_{0}^{R}(1+\varepsilon) \eta \psi d \eta\right) k C_{b}}{2 R L+\left[\frac{1}{2} \int_{0}^{R} \varepsilon(\eta) \eta d \eta\right] k C_{b}} \\
& =\frac{\int_{0}^{R}(1+\varepsilon) \eta \psi d \eta}{0.5+\int_{0}^{R} \varepsilon(\eta) \eta d \eta}
\end{aligned}
$$




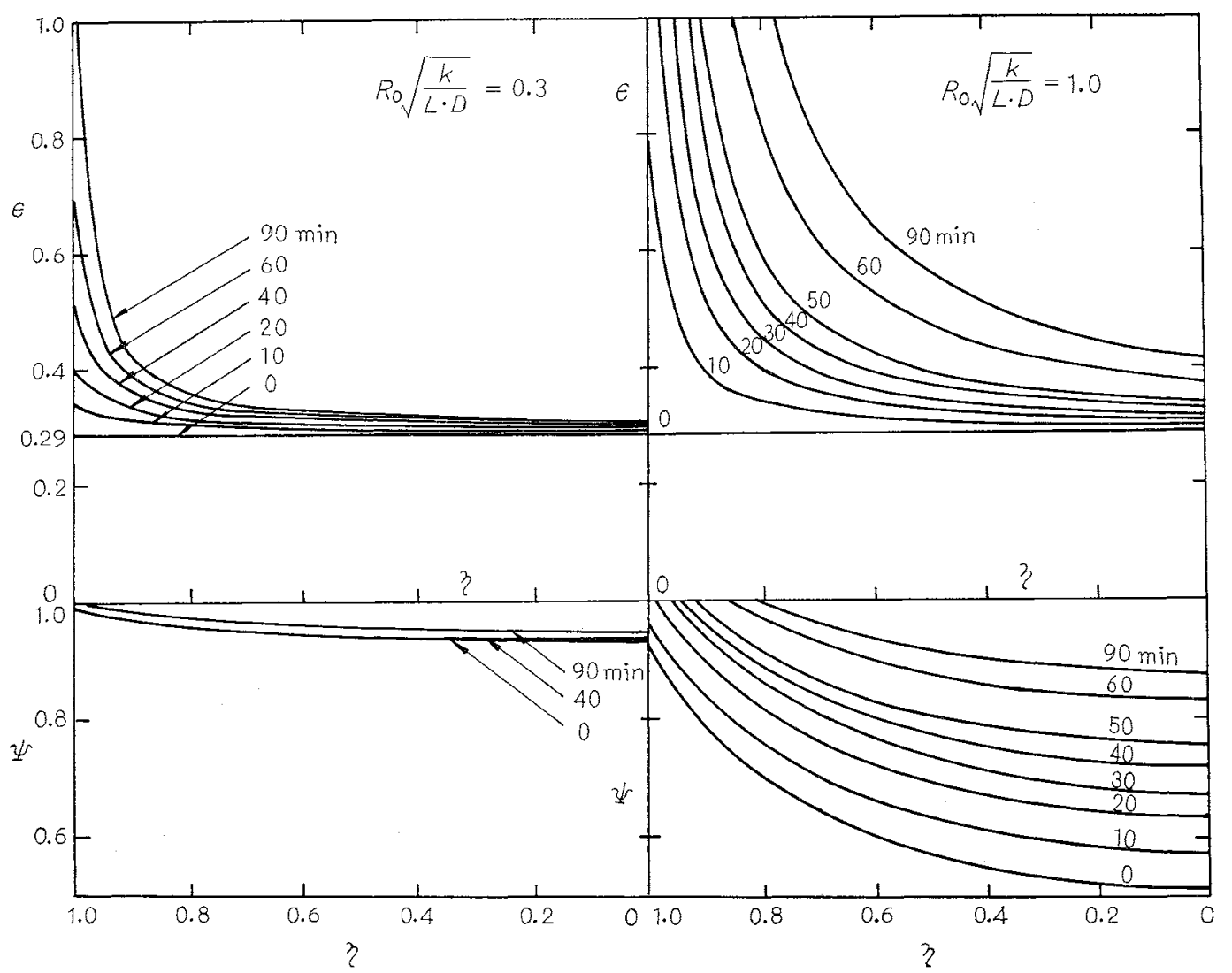

Fig. 2 Concentration and porosity profiles within solid

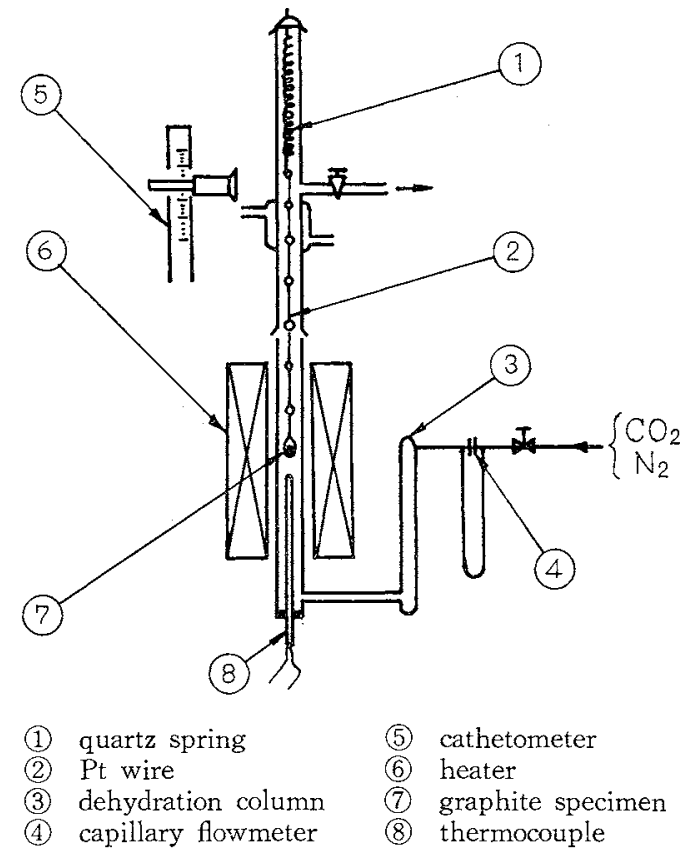

Fig. 3 Experimental apparatus

\begin{tabular}{lc}
\hline \multicolumn{1}{c}{ Table 1} & $\begin{array}{c}\text { Physical properties of graphite used } \\
\text { Sort }\end{array}$ \\
Eelctrode & (Tokai Electrode Co. Ltd.) \\
\hline True density & $2.2 \mathrm{~g} / \mathrm{cm}^{3}$ \\
Apparent density & $1.56 \mathrm{~g} / \mathrm{cm}^{3}$ \\
Porosity & 0.29 \\
Average pore radius & $(1.8)(10)^{-4} \mathrm{~cm}$ \\
\hline
\end{tabular}

\section{Experimental}

Experimental apparatus is shown in Fig. 3. The reactor, which consisted of a long quartz tube of $20 \mathrm{~mm}$ ID, was heated electrically $\left(\max .1200^{\circ} \mathrm{C}\right)$. The temperature at the center of the reactor was measured by means of an Alumel-Chromel thermocouple protected by an alumina pipe.

The graphite specimen was fabricated to a perfect sphere of $15 \mathrm{~mm}$ diameter. The physical properties of the graphite used are shown in Table 1.

The graphite sphere was suspended in the reactor by a platinum wire, which was connected to the quartz spring at the top. After being heated to a given temperature in a nitrogen stream, carbon dioxide was introduced at a predetermined flow rate for experimentation. The gas flow rate was measured by means of a capillary flow meter. Conversion was determined from the elongation of the spring.

\section{Results and Discussions}

Fig. 4 shows pictures of the cross sections of the sample specimen molded in plastics, which indicate the progress of reaction.

A good agreement was obtained between the experimental values of overall porosity and that calculated from Eq. (10), as shown in Table 2.

In Fig. 5, the experimental and theoretical data of conversion $Y$ vs. time are compared. The dotted lines 


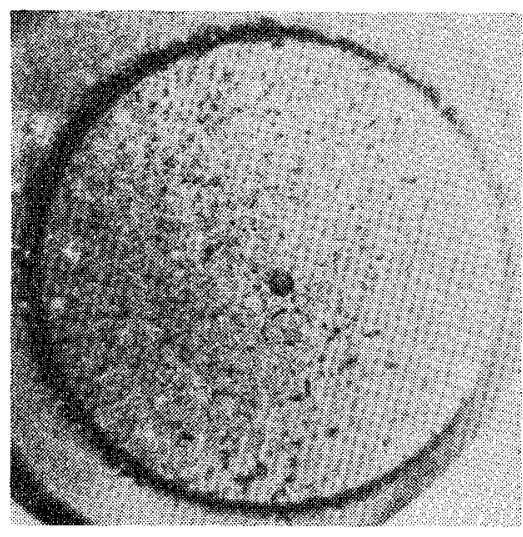

after $10 \mathrm{~min}$

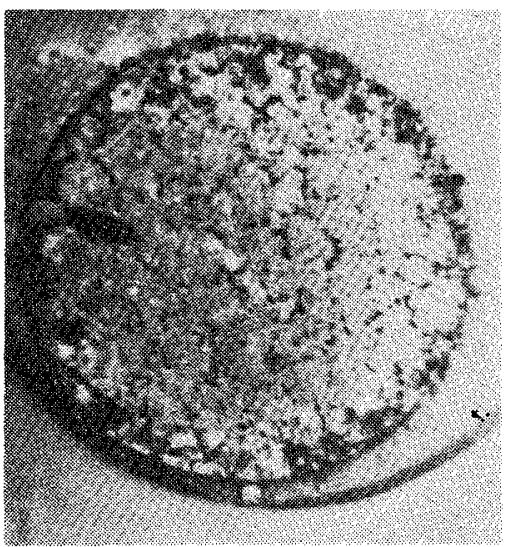

after $20 \mathrm{~min}$

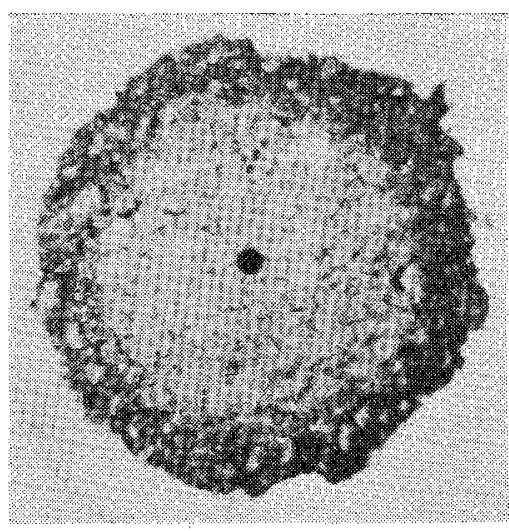

after $30 \mathrm{~min}$

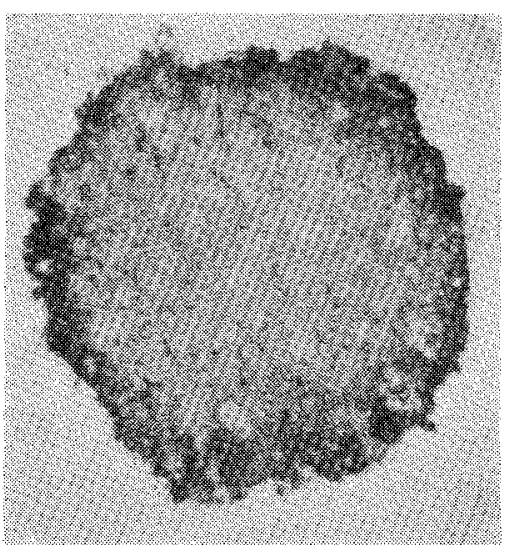

after $45 \mathrm{~min}$

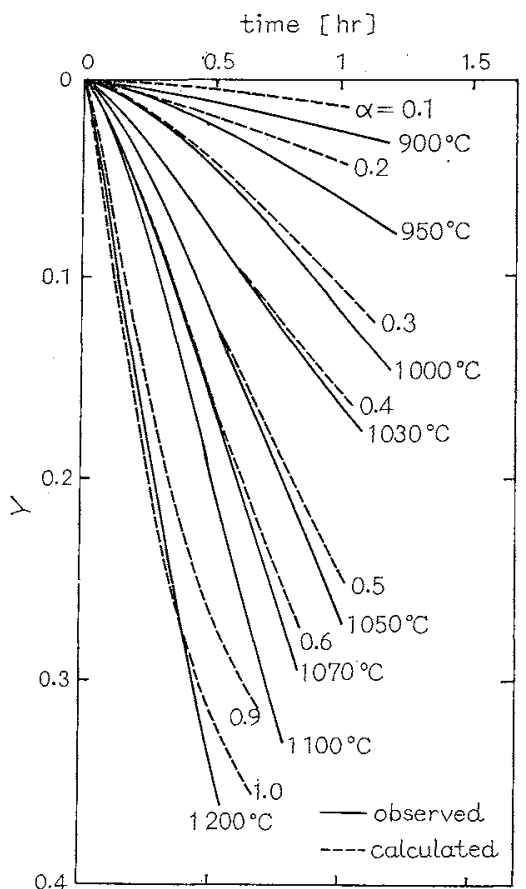

Fig. 5 Comparison of observed conversion with calculated results

Fig. 4 Cross-sectional photographs of the reacted graphite (at $1050^{\circ} \mathrm{C}$ )

\begin{tabular}{|c|c|c|c|c|}
\hline \multirow[t]{2}{*}{$\begin{array}{l}\text { Table } 2 \\
\text { values of }\end{array}$} & \multirow[t]{2}{*}{$\begin{array}{l}\text { Comparison between } \\
\text { overall porosity }\end{array}$} & \multicolumn{3}{|c|}{ observed and calculated } \\
\hline & & & Time & \\
\hline Temperature & Porosity & $10 \mathrm{~min}$ & $20 \mathrm{~min}$ & $30 \mathrm{~min}$ \\
\hline \multirow[t]{2}{*}{$1030^{\circ} \mathrm{C}$} & observed & 0.306 & 0. & 0.3 \\
\hline & calculated $(\alpha=0.4)$ & 0.307 & 0.324 & 0.342 \\
\hline \multirow[t]{2}{*}{$1050^{\circ} \mathrm{C}$} & observed & 0.320 & 0.335 & 0.364 \\
\hline & calculated $(\alpha=0.5)$ & 0.315 & 0.343 & 0.372 \\
\hline
\end{tabular}

in the figure represent the calculated results from Eq. (11), where the value of $4.0 \mathrm{~cm}^{2} / \mathrm{sec}$ derived by Wakao and Smith's equation ${ }^{12)}$ was used as the bulk diffusivity in the pore. The results in the initial stage of the reaction agree with Eq. (11).

The deviation in the latter stage may be due to the brittleness of the graphite sphere which causes breakoff and the additional weight loss of the sample, or the difference in estimation of the volume elements near the center. The size of the elements near the center may be the same as those near the surface, contrary to the assumption made in the model that they decrease concentrically.

It is necessary to know the value of $L$ in order to calculate the rate constant, $k$, from the value of $\alpha$ determined by the experimental data. The initial surface area can now be calculated from the total volume and average radius of pores obtained by the mercury displacement method. By equating this value with Eq.

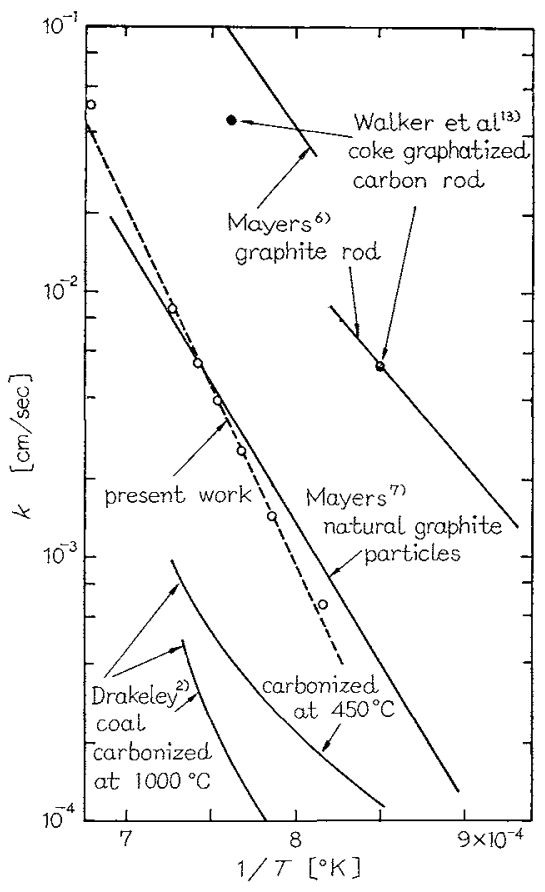

Fig. 6 Gasification rates by various investigators

(13), by which the initial surface area is given, the value $L$ is estimated to be nearly equal to $2.1 \times 10^{-3} \mathrm{~cm}$.

Fig. 6 shows the calculated values of the reaction rate 
constant. Also shown in this figure are the experimental data obtained by various investigators based on the assumption that the reaction takes place on the geometric surface exposed to the reacting gas. The calculated values of the present model are lower than the data obtained based on the geometric surface and are close to the data for finely divided particles.

The surface area ratio obtained from Eq. (14) and the effectiveness factor from Eq. (15) for typical values of $\alpha$ are shown in Fig. 7 and Fig. 8, respectively. The surface area ratios are supported, as seen in Fig. 7 , by the experimental data obtained in gasification of graphite cylinder by Wicke and Hedden ${ }^{14}$. It is interesting to note that the effectiveness factor is approximately unity

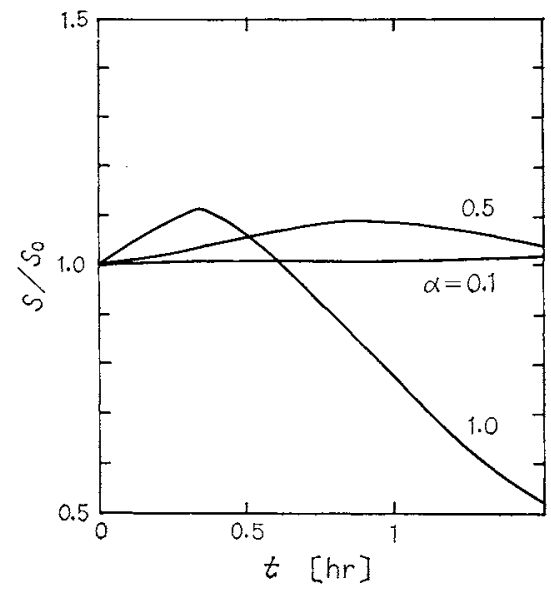

Fig. 7 Results of computation of surface area as function of $\alpha$ and time

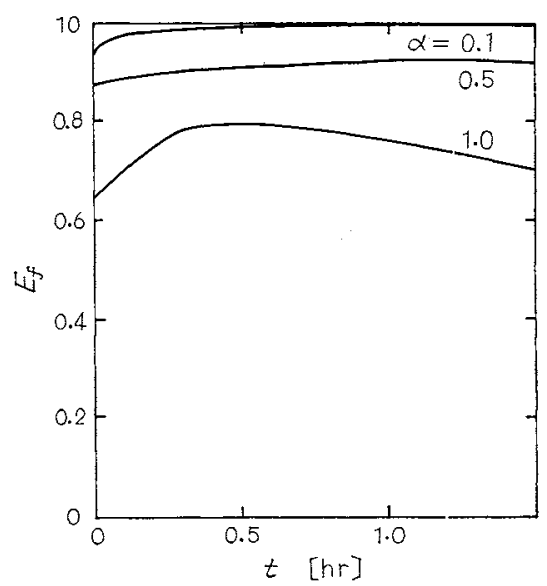

Fig. 8 Results of computation of effectiveness factor as function of $\alpha$ and time even at high temperatures.

\section{Acknowledgment :}

The authors wish to express their appreciation to Prof. K. Kawazoe who kindly offered the facilities of the mercury porosimeter.

\section{Nomenclature}

$a_{n}=$ coefficient as expressed in Eq. (7)

$b_{n}=$ coefficient as expressed in Eq. (7)

$C_{b}=$ bulk concentration of reacting gas

$C=$ concentration of reactant

$D=$ bulk diffusivity within pore

$d_{n}=$ coefficient as expressed in Eq. (7)

$E_{f}=$ effectiveness factor

$k=$ reaction rate constant

$L_{0}=$ length of both sides of volume element at sphere surface

$M=$ molecular weight of carbon

$R=$ radius of graphite sphere

$S=$ reaction surface area of graphite sphere

$t=$ time

$W=$ weight of graphite sphere

$Y=$ conversion

$\alpha=$ dimensionless parameter, $R_{0} \sqrt{\frac{k}{L D}}$

$$
\begin{array}{r}
{[-]} \\
{[-]} \\
{\left[\mathrm{mol} / \mathrm{cm}^{3}\right]} \\
{\left[\mathrm{mol}^{3} / \mathrm{cm}^{3}\right]} \\
{\left[\mathrm{cm}^{2} / \mathrm{sec}\right]} \\
{[-]} \\
{[-]} \\
{[\mathrm{cm} / \mathrm{sec}]}
\end{array}
$$

$\varepsilon=$ porosity

$\eta=$ reduced radius, $r / R_{0}$

$\nu=R / R_{0}$

$\rho=$ density of graphite

$\tau=$ reduced time, $\left(D / R_{0}{ }^{2}\right) t$

$\phi=$ reduced concentration, $C / C_{b}$

Subscript 0 refers to the initial value

$$
[\mathrm{cm}]
$$

$[\mathrm{g} / \mathrm{mol}]$

$[\mathrm{cm}]$

$\left[\mathrm{cm}^{2}\right]$

$[\mathrm{sec}]$

$[\mathrm{g}]$

$[-]$

$[-]$

$[-]$

$[-]$

$\left[\mathrm{g} / \mathrm{cm}^{3}\right]$

$[-]$

\section{Literature Cited}

1) Austin, L. G. and P. L. Walker, Jr.: A. I. Ch. E. Journal, 9, $303(1963)$

2) Drakeley, T. J.: J. Soc. Chem. Ind., 50, $319 \mathrm{~T}$ (1931)

3) Hawtin, P. and R. Murdoch: Chem. Eng. Sci., 19, 819 (1964)

4) Johnstone, H. F., C. Y. Chen and D. S. Scott: Ind. Eng. Chem., 44, 1564 (1952)

5) Khitrin, L. N.: 6th Sym. on Combustion, 565 (1957)

6) Mayers, M.A.: J. Am. Chem. Soc., 56, 70 (1934)

7) Mayers, M. A. : J. Am. Chem. Soc., 61, 2053 (1939)

8) Petersen, E. E.: A. I. Ch. E. Journal. 3, 443 (1957)

9) Prater, C. D.: Chem. Eng. Sci., 8, 284 (1958)

10) Rossberg, M. and E. Wicke: Chem.-Ing.-Techn., 28, 181 (1956)

11) Thiele, E. W.: Ind. Eng. Chem., 31, 916 (1939)

12) Wakao, N. and J. M. Smith: Chem. Eng. Sci., 17, 825 (1962)

13) Walker, Jr., P. L., R. J. Foresti, Jr. and C. C. Wright: Ind. Eng. Chem., 45, 1703 (1953)

14) Wicke, E. and K. Hedden: Z. Elektrochem., 57, 636 (1953)

15) Wicke, E.: Chem.-Ing.-Techn., 29, 305 (1957) 